\title{
The current dental school applicant: an overview of the admission process for UK dental schools and the sociodemographic status of applicants
}

\author{
Alessandra J. Booth, ${ }^{* 1}$ Katharine J. Hurry ${ }^{1}$ and Stefan Abela ${ }^{2}$
}

\section{Key points}

Provides an overview of the current admission processes for dental schools within the UK.
Encourages critical analysis of the admission processes used for undergraduate and postgraduate dental students.
Explores how the admission processes may change as a result of the COVID-19 pandemic and gives an indication as to the sociodemographics of the future dental career force.

\begin{abstract}
Aims To determine the current processes used to assess dental school admissions in the UK as well as compare the applicants' demography.
\end{abstract}

Methods All 16 dental schools in the UK were invited to complete a questionnaire analysing the admissions protocols between 2018-2019 and 2019-2020. These data were combined with the admission process information available online. Retrospective data from the University Clinical Aptitude Test including the sociodemographic status of dental applicants were collected. For the six dental schools that did not reply, data presented were collected from information available to the public.

Results The majority of applicants were women (63.2\% in 2019-2020), white (27.9\%) and are sixth form attendees or attend a further education college (40.6\%). Of those who apply to study dentistry, $15.5 \%$ are graduates who hold a first degree. For each undergraduate dental place available, there were 12.6 applicants and 9.4 applicants to each post-qualified dental undergraduate place.

Conclusion Further advancements are required to widen participation and broaden the sociodemographic status of dental applicants. This area would benefit from a long-term prospective study about recruitment methods and its correlation with performance at dental school. COVID-19 is impacting the application process, the full extent of which is yet to be determined.

\section{Introduction}

Admission into dentistry is a competitive and multifaceted process which aims to select students who will not only be able to complete the Bachelor of Dental Surgery programme but will also be expected to become full contributing members of the profession. Dentistry has been taught at universities in the UK for over 160 years, ${ }^{1}$ and throughout this period, the various application processes have evolved. It remains an increasingly desirable degree, despite around 800 individuals successfully gaining a place annually and this

${ }^{1}$ NIHR Dental Core Trainee Academic Clinical Fellow at the Institute of Dentistry, Faculty of Medicine and Dentistry, Queen Mary University of London, UK; ${ }^{2}$ Department of Oral Health, Norfolk and Norwich University Hospital, Norwich, UK. ${ }^{\star}$ Correspondence to: Alessandra J. Booth Email address: alessandra.booth@nhs.net

Refereed Paper.

Accepted 26 May 2021

https://doi.org/10.1038/s41415-022-3927-1 number growing year on year. ${ }^{2}$ Currently, 16 universities provide the course in the UK.

The majority of prospective dental school applicants apply for the university course that takes five years to complete and is offered at 14 out of the 16 universities. Applicants apply with predicted grades and secure their place on completion of their A-Level or equivalent examinations at age $17-18$ years.

To meet the current demand for undergraduate dentistry programmes, three universities also provide a postgraduate entry course. This course is generally four years long and is offered at King's College London (KCL) where the graduate entry-level students are combined with the undergraduates during their second year. The other two universities, the University of Central Lancashire and the University of Aberdeen, are providing a similar shorter programme for postgraduate applicants. The programme is a separate standalone course.

$\mathrm{KCL}$ also provides a three-year programme specifically for those who have a medical degree and wish to be dual qualified. ${ }^{3}$ The Dental Programme for Medical Graduates (DPMG) is typically completed by those embarking on a career in oral and maxillofacial surgery or oral medicine, although those who are medically qualified can also apply for fouryear postgraduate courses or the conventional five-year bachelor of dental surgery. Unfair admission and a disadvantageous position by applicants from state schools and from Black and Asian ethnic backgrounds has been well documented in the past. ${ }^{4}$ Similar findings were made available in a study analysing accessibility of Black and minority ethnic young people into nursing. Applicants from this type of background had less than half the chance of accessing nursing and midwifery training in comparison to white applicants. ${ }^{5}$ During the past few decades, the UK government has prioritised the accessibility of higher education by the wider public. ${ }^{6}$ Numerous strategies have been put in place to attract and retain nursing students. ${ }^{7}$ Specific to preclinical dentistry, Gallagher et al. (2009) have shown 
that the majority of applicants are more likely to be from higher social classes in comparison to other undergraduate courses. Applicants from an Asian background were four times more likely to apply in comparison to other courses and twice as much as for medical undergraduate courses. ${ }^{8}$ Strategies and models to widen access have also been suggested for medicine and dentistry. ${ }^{9}$ Graduate entry into medical school has also been shown to widen the sociodemographical aspect of medical school students. ${ }^{10}$

Clinical aptitude tests for selecting medical students have been doubted. The findings by Lambe et al. (2012) have shown that the University Clinical Aptitude Test (UCAT) may disadvantage some candidate groups. ${ }^{11}$

Most universities' official position is to support wider participation by being flexible with academic requirements for those who are from a lower socioeconomic background. Dundee and Glasgow universities offer the Reach Programme for dentistry, which is a national initiative that supports access to four professional programmes: medicine; dentistry; law; and veterinary medicine, with the principal aim of widening participation. The programme is threeyears long, is completed during secondary school and is directed to pupils who are considered to be socially disadvantaged. Such cohorts within the UK population include citizens that live in a Scottish Index of Multiple Deprivation decile $1-4 .{ }^{12} \mathrm{KCL}$ also offers an enhanced support course which provides academic support to individuals from state schools in Greater London who are completing the five-year degree.

Three universities, Bristol, Cardiff and Manchester, provide an extended six-year dental course which supports those who have not met the academic entry criteria. The additional training included as part of their dental degree in year six aims to close any gaps in knowledge and skills. Similarly, Liverpool University provides a foundation year with the aim of consolidating the acquired skills and knowledge to study dentistry. The applicants are required to reapply to the undergraduate dentistry course, following completion of the one-year course, separately. Previous research into the demographics of dental school applicants has indicated that the average dental applicant is a woman, aged 19.7 years and over half of applicants are from minority ethnic groups. Acceptance rates were lower for Black people, state school applicants and those from low socioeconomic backgrounds. ${ }^{13}$ A possible reason for this is lower academic grades and reduced access to desirable extracurricular requirements, such as the Duke of Edinburgh's award.
The aims of this study were to describe and analyse the current intake processes for entry into a number of dental university programmes. The demographics of the selected dental undergraduate students was also analysed to give an indication of the future profession's sociodemographic layout.

\section{Methods}

Applicants to UK dental schools submit their applications through the Universities and Colleges Admissions Service, UCAS. In total, 14 out of 16 schools require their applicants to sit the UCAT. Data were requested from UCAT and used to create a dataset providing an overview of the socioeconomic status of applicants in addition to whether they were successful in receiving an offer to read dentistry. Data were collected from two admission cycles: 2018-2019 and 2019-2020.

All 16 of the UK dental schools were contacted via both telephone and email with the request to complete a questionnaire stating their current admissions protocols. This included the years 2018-2019 and 2019-2020, alongside an additional question assessing how the COVID19 pandemic had impacted their application processes. Four of the dental schools contacted submitted our request automatically as a Freedom of Information (FOI) Act request. Six of the universities required the request to be submitted separately as a FOI and responded within the stated time frame. The data gained from the FOI Acts were combined with the information publicly provided by admissions teams on both the university websites and prospectuses, as well as previously published FOI requests. Six universities did not respond to the request in

\begin{tabular}{l|l|l}
\multicolumn{3}{l}{ Table 1 Demographic of dental applicants via UCAT for 2018-2019 and 2019-2020 } \\
\hline Demographic & $\mathbf{2 0 1 8 - 2 0 1 9}$ & $\mathbf{2 0 1 9 - 2 0 2 0}$ \\
\hline White & 900 & 890 \\
\hline Asian Pakistani & 458 & 503 \\
\hline Asian Indian & 426 & 472 \\
\hline Any other Asian background & 250 & 265 \\
\hline Any other ethnic group & 207 & 238 \\
\hline Black African & 135 & 143 \\
\hline Asian Bangladeshi & 97 & 120 \\
\hline White and Asian & 62 & 65 \\
\hline Asian Chinese & 51 & 38 \\
\hline Any other multiracial background & 42 & 44 \\
\hline White and Black Caribbean & 11 & 9 \\
\hline
\end{tabular}

the necessary timeframe and admission data for these universities were sourced indirectly from information available online through university websites and previous FOI requests.

The authors were unable to include a separate analysis of the data about the enhanced support, foundation and gateway courses due to a lack of information received. In addition, a number of the selected universities combine the data for these specific type of courses with their standard undergraduate dentistry course.

KCL's data for the Dentistry Entry Programme for Medical Graduates being the only university in the UK to provide it, could not be included as it would void anonymity.

\section{Results}

\section{Demographics}

UCAT data showed that the number of applicants to dentistry in the 2018-2019 cohort was 3,$051 ; 1,174$ men and 1,877 women. In 2019-2020, the number of applicants was very similar, at 3,187; 1,164 men and 2,015 women. This rendered the men to women ratio for 2018-2019 to be 38.5-61.5 percent respectively ( $\mathrm{M}: \mathrm{F}=38.5: 61.5$ ). Comparatively, in 2019-2020 the men to women ratio was slightly lower at 36.5 and 63.5 percent $(\mathrm{M}: \mathrm{F}=36.5: 63.5)$. In both cohorts, the trend showed that female applicants were far superior than their male counterparts. Of those that applied in 2018$2019,2,663$, or $87 \%$, were from the UK, 117 , or $4 \%$, were from the $\mathrm{EU}$, while 260 , or $9 \%$, were from neither of those locations. Similarly, in $2019-2020,2,817$, or $88 \%$, were from the $\mathrm{UK}, 97$, or $3 \%$, were from the EU, while 272 , or $9 \%$, were from neither of those locations. The demographic of applicants (as shown in Table 1) 
highlights that over half of applicants are from a minority ethnic background and the greatest represented demographic is white, followed by Asian Pakistani and Asian Indian for both years analysed. White and Black Caribbean were least represented.

From the UCAT data obtained it is evident that the majority of applicants hold school leaving qualifications such as A-levels or Scottish Highers: 2,466 in 2018-2019 and 2,558 in 2019-2020. In total, 553 applicants in 2018-2019 and 602 in 2019-2020 had an honours degree level or above including a Bachelor of Arts (BA), a Bachelor of Science (BSc), a Masters in Arts (MA), a Masters in Science (MSc) or a Doctorate in Philosophy (PhD). Overall, 21 applicants in 2018-2019 and 26 in 2019-2020 had no formal degrees. Table 2 shows the spread of locations from which individuals in the 2018-2019 and 2019-2020 cohorts applied. In both year groups, most applicants were from sixth form/further education college. Fewer applicants attended a comprehensive school in comparison to independent or private feepaying schools.

\section{Applicant selection}

At the time of writing, most dental schools within the UK utilise a combination of approaches to select applicants. The majority require predicted or achieved academic grades, typically A-level examination grades, aptitude tests, personal statements, academic references and interviews, either in traditional format or as multiple mini interviews (MMIs). The use of MMIs, aptitude tests and situational judgement tests (SJTs) have been shown through systematic review to be an effective method of selecting applicants ${ }^{14}$ and also to have a significant positive predictor for end-of-training assessments for medical counterparts. ${ }^{15}$

\section{Admissions tests}

For all undergraduate dental school programmes, aptitude tests are used as one of the criteria for selecting applicants. Fourteen undergraduate universities stated they used either the UCAT or the Biomedical Admissions Test (BMAT). Two of the post-graduate dental universities, Aberdeen and KCL, use the UCAT aptitude test in their selection process.

The UCAT, previously known as the UKCAT, was first developed in 2006 and is a multiple-choice-based exam taken on a computer in designated test centres. ${ }^{16}$ In

Table 2 Form of education as stated by dental applicants via UCAT for 2018-2019 and 2019-2020

\begin{tabular}{l|l|l}
\hline Location & $\mathbf{2 0 1 8 - 2 0 1 9}$ & $\mathbf{2 0 1 9 - 2 0 2 0}$ \\
\hline Sixth form/further education college & $\mathbf{1 , 2 1 6}$ & $\mathbf{1 , 2 9 5}$ \\
\hline Grammar & 424 & 472 \\
\hline University & 429 & 436 \\
\hline Independent/private fee-paying & 325 & 329 \\
\hline Comprehensive & 232 & 235 \\
\hline Other & 37 & 50 \\
\hline
\end{tabular}

Table 3 Range and mean UCAT cut-off score, highest aptitude score and lowest aptitude score for 2018-2019 and 2019-2020 cohorts from data provided by universities via completed questionnaires

\begin{tabular}{l|l|l|l|l}
\multicolumn{2}{l|}{ Years } & Aptitude cut-off score & Highest aptitude score & Lowest aptitude score \\
\hline \multirow{2}{*}{$\mathbf{2 0 1 8 - 2 0 1 9}$} & Range & $1,940-2,568$ & $2,800-3,380$ & $1,810-2,940$ \\
\cline { 2 - 5 } & Mean & $2,355.6$ & 3,050 & $2,289.09$ \\
\hline \multirow{2}{*}{$\mathbf{2 0 1 9 - 2 0 2 0}$} & Range & $2,280-2,548$ & $2,470-3,270$ & $2,040-2,548$ \\
\cline { 2 - 5 } & Mean & $2,443.6$ & $2,949.8$ & $2,266.8$ \\
\hline
\end{tabular}

2013, the test was adapted to include a noncognitive SJT. The exam currently comprises of five sections: verbal reasoning; decisionmaking; quantitative reasoning; abstract reasoning; and SJT. The first four sections are scored from 300-900 and the SJT from band 1-4, with 1 being the highest band. Six universities operate a UCAT cut off score which is determined depending on the scores of applicants for that year. Other universities use the score in conjunction with other application parameters, giving aptitude tests various weightings. Data provided by universities via completed questionnaires indicated the range and mean UCAT cutoff scores and the highest scores and lowest scores for entry cohorts 2018-2019 and 20192020 and these are tabulated in Table 3. A cross-sectional collaborative study across 12 medical schools indicated that UCAT results hold a weak predictive validity of medical school outcomes; ${ }^{17}$ however, research looking at undergraduate dental student performance after the first year of the programme found no link between exam performance and UCAT score. ${ }^{18}$ The use of the situational judgement band achieved by applicants varies between universities. Eight out of the sixteen institutions use the band as a differentiation tool to consider which applicants are offered a place. One study looking at the use of the SJT in the UCAT has suggested that it adds little value to making valid and reliable student selection decisions ${ }^{19}$ but further research needs to be undertaken in this domain. While the BMAT is used for several medical schools to assess applicants, it is not widely used by dental schools. Currently only one university, namely Leeds University, requires applicants to sit this test. The Graduate Medical School Admissions Test is used primarily by medical schools assessing graduate applicants; however, an exception to this is Plymouth University, which requires graduate applicants for dentistry to have sat the exam as part of their application.

\section{Academic requirements}

All UK universities require minimum academic standards. The majority require a minimum of three A grades (AAA) at A-level for consideration. Three universities required one of the A-Levels to be starred ( $\left.A^{\star} \mathrm{AA}\right)$, while one considered two B-graded A-Level examinations $(\mathrm{ABB})$ alongside the candidate's UCAT score. Prior research focusing on medical students has indicated that academic achievement at secondary school may give a good indication into both performance at medical school and in the medical career pathway. ${ }^{20,21}$

Some universities rank applicants using a point system that combines their academic achievement together with the UCAT score 
for determination of which candidates can be interviewed and potentially be given an offer (Fig. 1), while work experience, personal statement and references where considered as additional aspects.

\section{Interviews}

For 17 courses at 14 different dental schools, over 4,000 applicants were invited to interview: 4,287 in 2018-2019 and 4,578 in 20192020 , with an increase in the total number of applicants (Table 4). In the 2018-2019 application cycle, to each applicant, 0.46 interviews were allocated and of each applicant interviewed, 0.56 were offered a place. In 20192020 , for each applicant, 0.45 interviews were offered and of those interviewed, 0.54 were offered a place.

The choice of the interview panel members varied between the individual universities with many overlapping themes. For the dental universities that partook in the study, panel members ranged from dental students, academic staff, patients and clinical staff to lay representatives. While the traditional panel interview format was the interview of choice for many dental schools, there has been a surge in favour of MMIs. MMIs consist of several stations, each with a different interviewer with the aim of assessing different skills and attitudes. MMIs are used by 11 out of 14 dental schools to assess candidates. Three of the universities use traditional or panel interviews to select candidates, namely, Newcastle, Sheffield and Queen Mary's University. MMIs aim to overcome interviewer bias and offer an objective way of measuring candidate performance. ${ }^{22}$ Such stations may involve role playing with actors, manual dexterity tasks, discussing ethical issues or dental public health topics. MMIs are perceived favourably by both candidates and interviewers. ${ }^{23}$ MMIs have also been found to be a reliable tool to predict behavioural traits associated with professionalism demanded by the nature of
Fig. 1 The most common applicant selection process adopted by UK dental schools

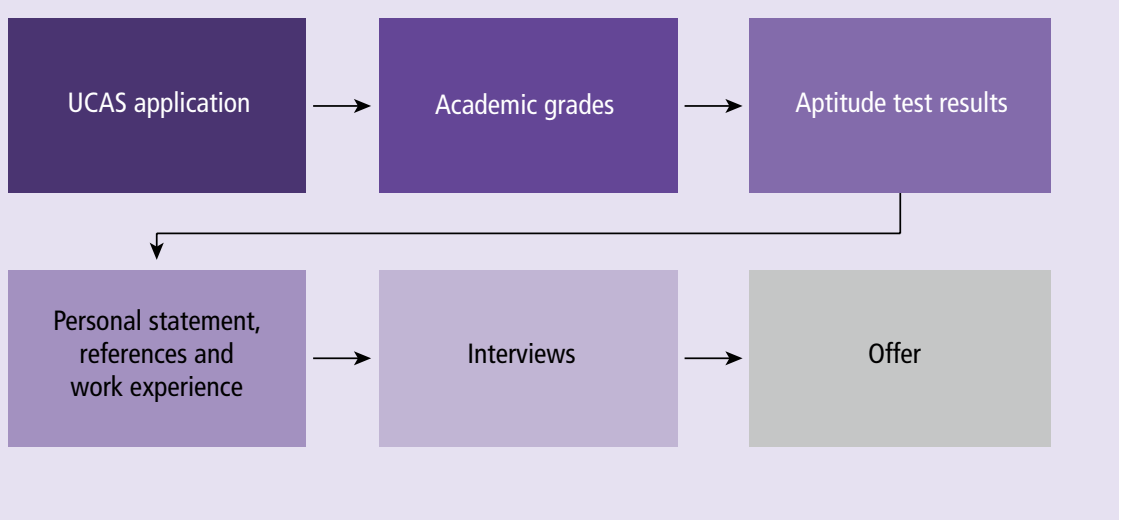

the profession. ${ }^{24} \mathrm{~A}$ positive correlation was also identified between MMIs and future academic performances by the entrants. ${ }^{25} \mathrm{~A}$ systematic review looking into the efficacy and reliability of MMIs for the selection of healthcare professional undergraduate programmes has also shown positive outcomes describing them as reliable, acceptable and feasible tools for selection. ${ }^{26}$

\section{Dentistry-specific qualities}

In addition to academic achievements, aptitude tests and interviews, dental schools assess applicants for personal qualities specific to dentistry. Evidence of work experience relating to dentistry and the healthcare profession is required by nine of the universities. Two of those universities specified the length of work experience desired, ranging from three days to two weeks. While work experience may increase an applicant's understanding of the profession and demonstrate a motivation to study the subject, personal statements and work experience have been suggested to disadvantage applicants from lower socioeconomic groups and those attending state schools. ${ }^{13,27}$ All but one of the 16 universities consider the personal statement when selecting applicants and assess traits such as leadership, teamwork, commitment to dentistry, self-motivation and resilience. Eight universities considered references when choosing candidates for an interview.

\section{Offers}

The number of offers made to applicants from the 14 universities included has only marginally reduced: 2,467 for the 2018-2019 cohort to 2,465 for 2019-2020 (Table 4). Six dental courses made fewer offers in 2019-2020 whereas ten courses gave more offers, although these differences are marginal. One of the universities offering postgraduate degrees gave an offer to every applicant they interviewed for the two-year time-frame analysed.

The number of places available from 11 of the dental schools also increased from 795 for the 2018-2019 cohort to 822 in 2019-2020 (Table 4). Four of the dental schools failed to supply data relating to the number of places available. Two universities keep a set number of places available for international students.

\section{Short-term impact of COVID-19}

Due to the COVID-19 pandemic, university admission processes were reviewed by many of the above-mentioned universities. The review

Table 4 Comparison of postgraduate and undergraduate number of interviews, offers and places available for 2018-2019 and 2019-2020

\begin{tabular}{|l|l|l|l|l}
\hline Dental course & Number of applicants & Number of applicants invited to interview & Number of applicants offered a place & Number of places available \\
\hline Undergraduate & Out of $\mathbf{1 1}$ universities & Out of $\mathbf{1 2}$ universities & Out of $\mathbf{1 2}$ universities & Out of $\mathbf{9}$ universities \\
\hline $2018-2019$ & 8,612 & 4,019 & 2,334 & 721 \\
\hline $2019-2020$ & 9,365 & 4,308 & 2,317 & 743 \\
\hline Postgraduate & Out of $\mathbf{3}$ universities & Out of $\mathbf{3}$ universities & Out of $\mathbf{3}$ universities & Out of $\mathbf{3}$ universities \\
\hline $2018-2019$ & 763 & 268 & 133 & 74 \\
\hline $2019-2020$ & 740 & 270 & 148 & 79 \\
\hline
\end{tabular}


allowed for the reduction in unnecessary travel, social distancing requirements and the impact of candidates requiring to self-isolate or becoming unwell. The pandemic has also resulted in a shift of A-level examinations assessments as students have faced a reduction in face-to-face schooling. Additionally, the government announced that the GCSE, AS-level and A-level examinations will not take place in summer 2021. Teacher assessments have been used as a replacement methodology and this will introduce an element of bias and potentially disadvantage students from certain sociodemographical areas. Speculatively, the pandemic might have allowed prospective dental undergraduate candidates to experience negative impacts on their application outcomes. Negative experiences would have also been featuring in work experience fields, with reduced extra-curricular activities and extended periods off school influencing academic outcomes. Some universities have accounted for this when assessing applications. Glasgow University is the only university to make an official statement on the impact of COVID-19 pandemic. Their position on this is that due to the impact the pandemic had on their personal statements and extracurricular activities, work experience is not on the essential nor desired list of requirements for the 2021/2022 entry. Nine universities have adapted their intake methodology by conducting virtual interviews in contrast to face-to-face interviews. It is unknown how these factors will influence the future cohort of undergraduate dental students.

\section{Conclusion}

This article highlights the similarities in approaches made by universities within the UK in selecting prospective applicants to their respective bachelor of dental surgery courses. Nevertheless, the final entrants selected as dental undergraduate students are very diverse and of very different ethnic backgrounds.

Based on the findings in this study, the following conclusions can be drawn:

1. Further advancements are required to widen participation and broaden the sociodemographic status of dental applicants
2. The universities would benefit from a longterm prospective study about the selection and recruitment methods and analyse their correlation with performance at dental school

3. COVID-19 is impacting the application process, the full extent of which is yet to be determined.

It is also reassuring to see that advances have been made by the profession to drive the diversity in applicants by introducing widening participation courses and alterations to the application process, including MMIs. The impact of the pandemic could be an opportunity to develop consistency between the universities and strengthen the accuracy of their application process for a more diverse and dedicated cohort of students.

Ethics declaration

The authors declare no conflicts of interest.

\section{Author contributions}

Dr Alessandra Joelle Booth helped with writing of the article, article submission and responding to peer review. Dr Katharine Julia Hurry helped with data collection, coordination with universities and data interpretation. Dr Stefan Abela helped with the proposal of the subject for the paper, article review and responding to peer review.

\section{References}

1. Gelbier S. Dentistry and the University of London. Med Hist 2005; 49: 445-462.

2. Office for Students. Medical and dental intakes. 2019. Available at https://www.officeforstudents.org.uk/ advice-and-guidance/funding-for-providers/healtheducation-funding/medical-and-dental-intakes/ (accessed December 2020).

3. Chadha A, Dastaran M, Herd M K. The first UK dental undergraduate programme for medical graduates $-\mathrm{a}$ student perspective. Br Dent J 2009; 206: 353-354.

4. Boliver V. How fair is access to more prestigious UK universities? Br J Sociol 2013; 64: 344-365.

5. Grainger K. Equal access to training for black and minority ethnic nurses. Nurs Stand 2006; 20: 41-49.

6. Croxford L, Docherty G, Gaukroger R, Hood K. Widening Participation at the University of Edinburgh: Contextual Admissions, Retention, and Degree Outcomes. Scottish Affairs 2014; 23: 192-216.

7. Gilchrist K L, Rector C. Can you keep them? Strategies to attract and retain nursing students from diverse populations: best practices in nursing education. J Transcult Nurs 2007; 18: 277-285.

8. Gallagher J E, Niven V, Donaldson N, Wilson N H F. Widening access? Characteristics of applicants to medical and dental schools, compared with UCAS. $\mathrm{Br}$ Dent J 2009; 207: 433-445.
9. Kamali A W, Nicholson S, Wood D F. A model for widening access into medicine and dentistry: the SAMDA-BL project. Med Educ 2005; 39: 918-925.

10. James D, Ferguson E, Powis D, Symonds I, Yates J. Graduate entry to medicine: widening academic and socio-demographic access. Med Educ 2008; 42: 294-300.

11. Lambe P, Waters C, Bristow D. The UK Clinical Aptitude Test: is it a fair test for selecting medical students? Med Teach 2012; DOI: 10.3109/0142159X.2012.687482.

12. Scottish Government. Scottish Index of Multiple Deprivation 2020. 2020. Available at https://www. gov.scot/collections/scottish-index-of-multipledeprivation-2020/ (accessed January 2021).

13. Niven V, Andiappan M, Cabot L, Gallagher J E. Embarking on a professional career: social advantage in dentistry and medicine. UK dental and medical student applications and admissions, 1996-2011. Br Dent J 2019; 227: 411-418.

14. Patterson F, Knight A, Dowell J, Nicholson S, Cousans $F$, Cleland J. How effective are selection methods in medical education? A systematic review. Med Educ 2016; 50: 36-60.

15. Patterson F, Rowett $E$, Hale R et al. The predictive validity of a situational judgement test and multiplemini interview for entry into postgraduate training in Australia. BMC Med Educ 2016; 16: 87.

16. UCAT. UCAT Consortium. Available at https://www. ucat.ac.uk/about-us/ (accessed January 2021).

17. McManus I C, Dewberry C, Nicholson S, Dowell J S. The UKCAT-12 study: educational attainment, aptitude test performance, demographic and socio-economic contextual factors as predictors of first year outcome in a cross-sectional collaborative study of 12 UK medical schools. BMC Med 2013; 11: 244.

18. Lala R, Wood D, Baker S. Validity of the UKCAT in applicant selection and predicting exam performance in UK dental students. J Dent Educ 2013; 77: 1159-1170.

19. Lambe P, Kay E, Bristow D. Exploring uses of the UK Clinical Aptitude Test-situational judgement test in a dental student selection process. Eur J Dent Educ 2018; 22: 23-29.

20. Adam J, Bore M, Childs R et al. Predictors of professional behaviour and academic outcomes in a UK medical school: A longitudinal cohort study. Med Teach 2015; 37: 868-880.

21. McManus I C, Woolf K, Dacre J, Paice E, Dewberry C. The Academic Backbone: Iongitudinal continuities in educational achievement from secondary school and medical school to MRCP(UK) and the specialist register in UK medical students and doctors. BMC Med 2013; 11: 242.

22. Pau A, Chen Y S, Lee V K M, Sow C F, De Alwis R. What does the multiple mini interview have to offer over the panel interview? Med Educ Online 2016; DOI: 10.3402/ meo.v21.29874.

23. McAndrew $R$, Ellis J. An evaluation of the multiple miniinterview as a selection tool for dental students. Br Dent J 2012; 212: 331-335.

24. Duff R E, Katcher P A, Daniels R M, Ramaswamy V. The Multiple Mini Interview as a Dental School Admission Tool: Can It Predict Noncognitive Traits Associated with Professional Behaviours? J Dent Educ 2020; 84: 478-485.

25. Alaki S M, Yamany I A, Shinawi L A, Hassan M H A, Tekian A. Can Multiple Mini-Interviews Predict Academic Performance of Dental Students? A Two-Year Follow-Up. J Dent Educ 2016; 80: 1376-1383.

26. Pau A, Jeevaratnam K, Chen YS, Fall A A, Khoo C, Nadarajah V D. The Multiple Mini-Interview (MMI) for student selection in health professions training - a systematic review. Med Teach 2013; 35: 1027-1041.

27. Wright $S$. Medical school personal statements: a measure of motivation or proxy for cultural privilege? Adv Health Sci Educ Theory Pract 2015; 20: 627-643. 